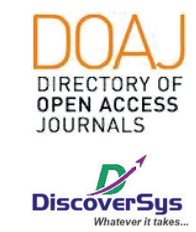

Published by DiscoverSys

\section{The physiological aspect of thyroid-induced breast cancer: A case report}

\author{
Putu Austin Widyasari Wijaya*
}

CrossMark

\title{
ABSTRACT
}

Background: Breast cancer has the second-highest prevalence of cancer in Indonesia. The aetiology of breast cancer involves endogenous sex hormone activity, estrogen. Besides, thyroid hormones have estrogen-like effects on breast tissue which are thought to play a role in the development of breast cancer. This case report aims to evaluate the physiological aspect of thyroid-induced breast cancer.

Case Report: A 49-year-old Balinese woman came to the Primary Health Care with a history of uncontrolled hyperthyroidism for 5 years (2014-2019), complaining of a lump in her left breast. Open biopsy and immunohistochemistry were done (Grade III Invasive Carcinoma ER + $50 \%$, Her $+2-3)$. Patients were diagnosed with stage $3 \mathrm{~B}$ breast cancer and conservative treatment has been taken. The examination of TSH thyroid hormone was $0.204 \mu \mathrm{lU} / \mathrm{mL}$ (normal $=0.5-6 \mu \mathrm{lU} / \mathrm{mL}$ ) and FT4 $3.1 \mathrm{ng} / \mathrm{dL}$ (normal $=0.7-1.9 \mathrm{ng} / \mathrm{dL}$ ). The primary management of patients was chemotherapy following by Modified Radical Mastectomy (MRM), hormone suppressant injection, as well as Herceptin. Those medications were effective in reducing the development of breast cancer through thyroid hormone pathway.

Conclusion: Some studies showed hyperthyroidism increase the risk of breast cancer and that high thyroid levels can cause estrogen-like effects, trigger proliferation and angiogenesis by activating the same pathway as estrogen those are mitogen-activated protein kinase (MAPK) and extracellular signal-regulated kinase $1 / 2$ (ERK 1/2).
Postgraduate Student, Department of Physiology, Faculty of Medicine, Universitas Udayana, Bali, Indonesia

*Correspondece to: Putu Austin Widyasari Wijaya; Postgraduate Student, Department of Physiology, Faculty of Medicine, Universitas Udayana, Bali, Indonesia; austinwijaya.aw@gmail.com

Received: 2019-09-17 Accepted: 2020-01-03 Published: 2020-03-03

Keywords: breast cancer, hyperthyroidism, estrogen hormone, thyroid hormone, estrogen-like effect.

Cite this Article: Wijaya, P.A.W. 2020. The physiological aspect of thyroid-induced breast cancer: A case report . Intisari Sains Medis 11(1): 100-103. D01: 10.15562/ism.v11i1.621

\section{INTRODUCTION}

Cancer is recently known has a higher prevalence in Indonesia since decades. One of them is breast cancer having the second highest prevalence in Indonesia. ${ }^{1}$ In 2019, the incidence of breast cancer was 42.1 per 100,000 people with an average mortality rate of 17 per 100,000 population. ${ }^{2,3}$ The causes of breast cancer are multifactorial, including genetic factors, hormonal factors, and lifestyle. ${ }^{3}$ In addition, several hematological markers have also been evaluated to the determine the risk and subtype-related breast cancer., ${ }^{4,5}$ The hormonal factor that is known to play a significant role in the pathophysiology of breast cancer is the hormone estrogen. Estrogen affects the proliferation and differentiation of breast tissue. ${ }^{1,6}$

Some studies show that there is an estrogen-like effect caused by high levels of thyroid hormones in the blood. ${ }^{7,8}$ In the pathophysiology of breast cancer itself, several estrogen receptors can be activated by thyroid, both directly and indirectly. ${ }^{9}$ This shows that, on a pathophysiological basis, these two diseases (hyperthyroidism and breast cancer) have a reasonably close relationship and have been proven through large-scale studies and in vitro. ${ }^{7,8}$ Based on those mentioned above, this case report aims to evaluate the cellular and molecular interactions between thyroid hormones and breast cancer from physiological aspect.

\section{CASE DESCRIPTION}

Female, 49 years old, Indonesian citizen, Balinese with a history of hyperthyroidism for 5 years (since 2013), complaining of a lump in the left breast. Lumps are felt for one month, increase in size and pain during menstruation. The patient had a history of treatment for hyperthyroidism with propylthiouracil (PTU) for two years (irregular) and neo-mercazole (carbimazole) for the past 2 years. In addition, we also found a history of autodidact discontinuation of medications.

Examination of TSH thyroid hormone $0.204 \mu \mathrm{IU} / \mathrm{mL}$ (normal $=0.5-6 \mu \mathrm{IU} / \mathrm{mL}$ ) and FT4 $3.1 \mathrm{ng} / \mathrm{dL}$ (normal = $0.7-1.9 \mathrm{ng} / \mathrm{dL}$ ). Breast ultrasound examination, in the left breast irregular heterogeneous solid nodules with necrotic edges, nodule size $6.5 \times 6.5 \mathrm{~cm}$ (Figure 1 ). The action of open biopsy was carried out and obtained the results of cytology PA Invasive Carcinoma No Special Type III. Immunohistochemical examination was carried out with $\mathrm{ER}+50 \%$ (strong intensity), $\mathrm{PR}+1 \%$ (light intensity), Her-2 3+, and Ki-67 50\%. Based on the examination above the patient was diagnosed with stage $3 \mathrm{~B}$ breast cancer (T3N1M0) or also called Sinistra's Locally Advanced Breast Cancer (LABC). Management in patients given neoadjuvant chemotherapy for 4 cycles, then reevaluated to determine the action of removal of the tumour. 


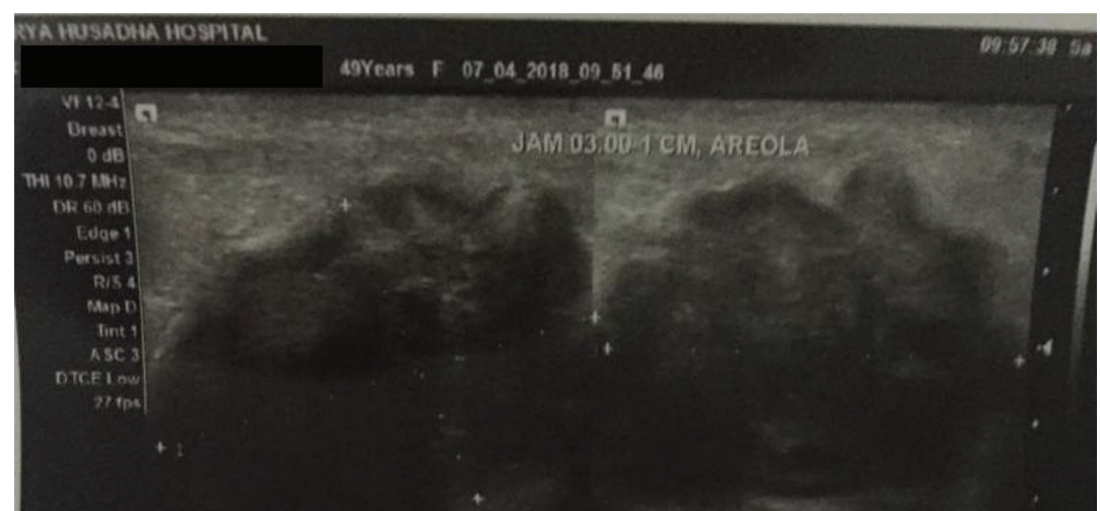

MAMMA KI

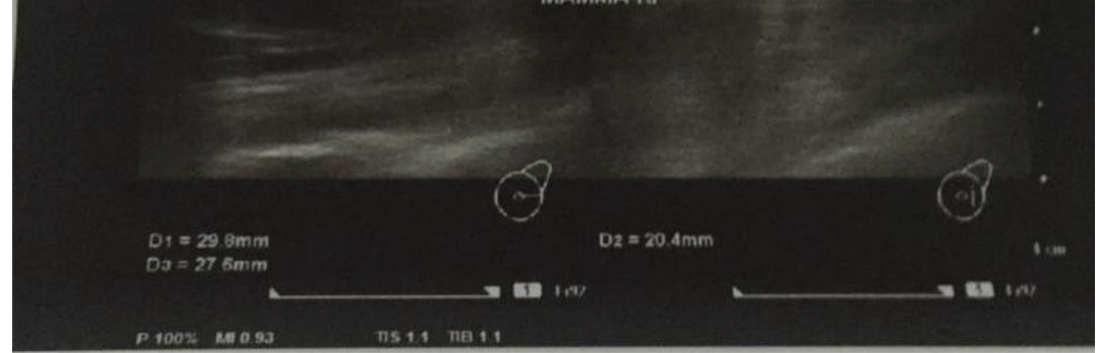

Figure 1 The Ultrasonography (USG) picture of mammae dextra and sinistra before chemotherapy (tumour size $6.5 \times 3.4 \times 6.5 \mathrm{~cm}$ )

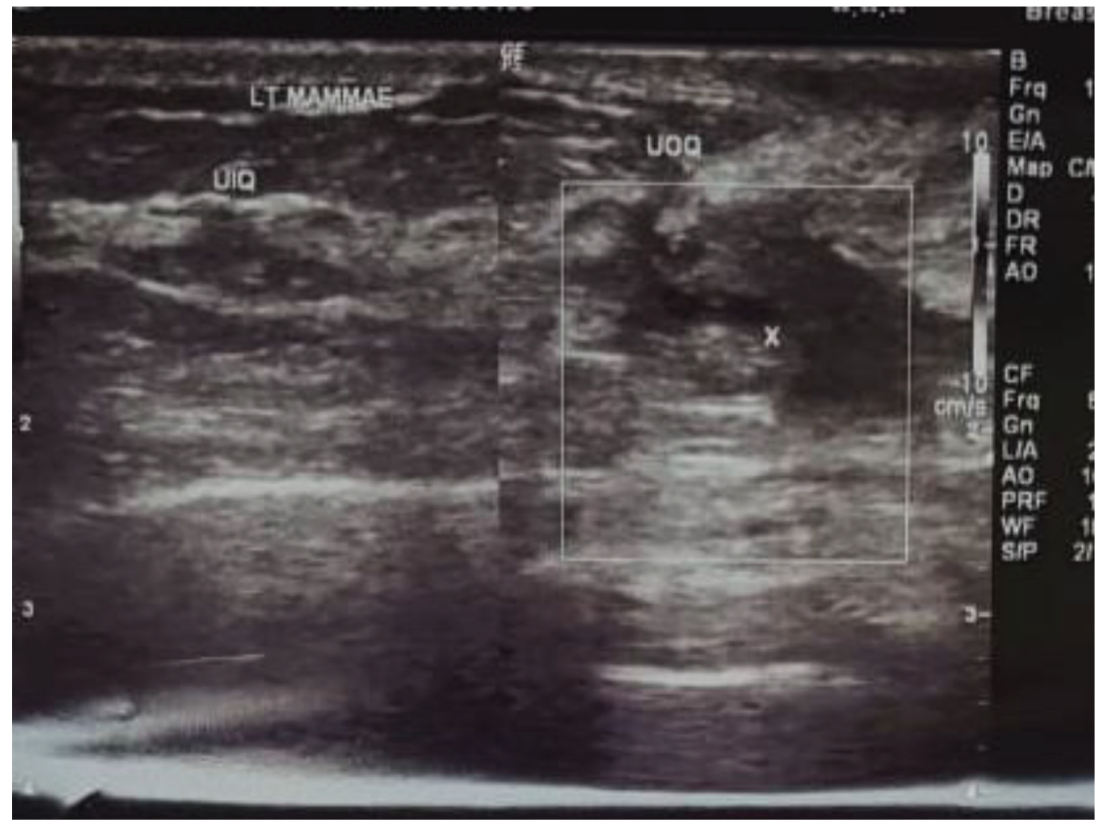

Figure 2 Ultrasonography (USG) evaluation of breast cancer after 4 cycles chemotherapy (tumor size $2.6 \times 1,7 \times 2,6 \mathrm{~cm}$ )

Chemotherapy given to patients is doxorubicin and paclitaxel for 4 cycles. The effects of tumour chemotherapy shrink with a size of $3.8 \times 3 \mathrm{~cm}$ on physical examination. Furthermore, the patient was treated with a Modified Radical Mastectomy (MRM) and a cytology examination of the tumour tissue removed (Figure 2).

Cytology examination results showed tumours with a size of $10 \times 7.5 \times 2.5 \mathrm{~cm}$, the distance of mass to the skin $1 \mathrm{~cm}$, to the base of $1 \mathrm{~cm}$. The mass consists of the proliferation of neoplastic epithelial cells forming a solid infiltrative structure between the tissue stroma. Neoplastic epithelial cells show a rounded appearance, eosinophilic cytoplasm, round nucleus, moderate core pleomorphic, increased N / C ratio, irregular and hyperchromatic core membrane, and positive invasion. Cytology results concluded with partial response chemotherapy, there were malignant cell metastases in 3 of the 8 lymph node structures, no metastasis in the axillary tail and classified as ypT3N1Mx.

After the MRM action, adjuvant chemotherapy was continued in 2 cycles (doxorubicin and paclitaxel). Then, the patient was followed by oral therapy in the form of tamofen (Tamoxifen) and estrogen hormone suppressant therapy (Zoladex) for 6 cycles and 25 cycles of radiotherapy. Giving Herceptin therapy for Her $3+$ is still considered in this case.

\section{DISCUSSION}

Thyroid hormones have interactions with sensitive estrogen tissue, one of which is breast tissue. ${ }^{6}$ Several studies show an association between autoimmune thyroid disease and breast cancer. A cohort study conducted on a large scale in Asia showed a significantly increased risk of breast cancer in hyperthyroid patients under 55 years of age. ${ }^{8}$ This increased risk is thought to be the effect of high levels of thyroid hormones. A large-scale cohort study in Denmark showed an increased risk of breast cancer in women with hyperthyroidism and a slightly reduced risk of breast cancer in women with hypothyroidism. ${ }^{7}$ In the study it was concluded that thyroid hormone levels influence breast tissue. $^{7,8}$

In cases, patients with a history of hyperthyroidism for $>3$ years, history of treatment is not controlled, and have symptoms of breast cancer with rapid onset ( $<6$ months). As explained in several studies above, uncontrolled thyroid hormone levels have estrogen-like effects and are rapidly thought to produce changes in malignancy or malignancy in breast tissue. A study shows a specific disorder in thyroid hormone receptors (TRs) found in breast cancer and has a role in the regulation of oncogenes. ${ }^{6-8}$

In vitro studies have shown that high thyroid levels can cause estrogen-like effects and trigger proliferation and angiogenesis. ${ }^{6,9}$ It is known that molecular interactions between estrogen and thyroid hormones occur through two pathways, namely the nuclear and non-nuclear pathways. The non-nuclear pathway is known to be thyroid hormones, and estrogen activates mitogen-activated protein kinase (MAPK). 
MAPK and extracellular signal-regulated kinase $1 / 2$ (ERK $1 / 2$ ) mobilize the cytoplasm to stimulate growth and cell division. ${ }^{6,9}$

Active Triiodothyronine (T3) itself was also found to trigger breast cancer cell proliferation through upregulation of estrogen response element (ERE) - mediated gene transcription and increase the effect of 17beta-oestradiol-mediated cell proliferation in breast cancer cells. ${ }^{10}$ In the population study, T3 levels showed a positive association with tumour size in breast cancer and the risk of lymph node metastasis. In the nuclear pathway, thyroid hormones and estrogen have effects on transcriptional changes that inhibit the apoptotic process and induce cellular proliferation. ${ }^{9}$

It is known that estrogen has a large role in the pathophysiology of breast cancer. ${ }^{10}$ As explained above, estrogen triggers the proliferation of breast cells through the expression of the estrogen receptor itself (ER-estrogen receptor). ${ }^{9}$ High estrogen exposure caused by several precipitating factors causes excessive ER induction which results in active estrogen response element (ERE). Active ERE disrupts regulation of transcription factors, so that cell proliferation is disrupted, leading to uncontrolled proliferation. Based on existing research, where the thyroid is thought to have estrogen-like effects, and trigger estrogen receptors (ER) so that high levels will also activate ERE and cause disruption of breast cell proliferation. ${ }^{9,10}$

In addition to estrogen receptors, the human epidermal growth factor receptor-2 (HER2) also plays a role in the pathophysiology of breast cancer. ${ }^{3,6}$ HER2 is a receptor tyrosine kinase that is expressed in normal and cancerous tissue and has extracellular, transmembrane, and intracellular ligand-binding domains. ${ }^{10}$ This causes HER2 to more easily form dimers with other molecules and HER2 capable of influencing several cellular functions through varied pathways. The binding of the HER2 ligand will stimulate phosphorylation of tyrosine residues in the intracellular domain of HER2, causing activation of multiple downstream signaling pathways including the pathway of mitogen-activated protein kinase (MAPK) and phosphatidylinositol 4.5-bisphosphate 3-kinase (PI3K). The pathway is closely related to the development of breast tumours. This pathway can also be activated by thyroid hormones which are high in the blood. ${ }^{9,10}$

Besides thyroid hormone, the risk factor that also plays a role in the incidence of breast cancer, in this case, is that the patient unmarried, so the patient has never breastfed. It is known that breastfeeding is one of the protective factors of breast cancer. Breastfeeding can play a role in reducing endogenous sex hormone levels. ${ }^{3,7,9}$

\section{CONCLUSION}

In this case, uncontrolled hyperthyroidism is a major risk factor that plays a role in the development of breast cancer in patients. Inadequate reduction in thyroid hormone levels due to uncontrolled treatment causes an increase in estrogen-like effects and triggers proliferation of breast tissue. The mechanism of thyroid hormones in triggering breast cancer is might be involved in the stimulation of estrogen receptors (ER) and Human epidermal growth receptor-2 (HER2) in accordance with immune histochemical results in patients. However, author suggests that further studies should be made regarding the interrelationship between breast cancer risk factors and their implications for the incidence of breast cancer.

\section{CONFLICT OF INTEREST}

There is no conflict interest regarding publication of the current case report.

\section{FUNDING}

None

\section{AUTHOR CONTRIBUTION}

All of the authors are equally contributed to the study from the data gathering, physical examination, supporting investigation, until reporting the results of the case.

\section{REFERENCES}

1. Ramli M. Update Breast Cancer Management, Diagnostic, and Treatment. Majalah Kedokteran Andalas. 2015;38(Suppl 1):28-53

2. DeSantis CE, Ma J, Gaudet MM, Newman LA, Miller KD, Goding Sauer A, et al. Breast cancer statistics, 2019. CA Cancer J Clin. 2019;69(6):438-451.

3. Shah R, Rosso K, Nathanson SD. Pathogenesis, prevention, diagnosis and treatment of breast cancer. World J Clin Oncol. 2014;5(3):283-98.

4. Lestari AAW, Prabawa IPY, Wiranata S, Supadmanaba IGP. High eosinophils lymphocyte ratio (ELR) related with subtype of breast cancer in Sanglah General Hospital, Bali. Annals of Oncology. 2018;29(Suppl 9):ix11-ix12.

5. Wiranata S, Adiputra PAT, Lestari AAW, Prabawa IPY, Supadmanaba IGP. Platelet Lymphocyte Ratio (PLR) Related with Clinicopathological Characteristics of Balinese Women Breast Cancer Patient. Annals of Oncology. 2019;30(Suppl 6):vi144. 
6. Ditsch N, Liebhardt S, Koch FV, Lenhard M, Vogeser M, Spitzweg C, et al. Thyroid function in breast cancer patients. Anticancer Res. 2010;30(5):1713-7.

7. Søgaard M, Farkas DK, Ehrenstein V, Jørgensen JO, Dekkers OM, Sørensen HT. Hypothyroidism and hyperthyroidism and breast cancer risk: a nationwide cohort study. Eur J Endocrinol. 2016;174(4):409-14.

8. Weng $\mathrm{CH}$, Chen $\mathrm{YH}$, Lin CH, Lou X, Lin TH. Thyroid disorders and breast cancer risk in Asian population: a nationwide population-based case-control study in Taiwan. BMJ Open. 2018;8(3):e020194.

9. Siegler JE, Li X, Jones SD, Kandil E. Early-onset breast cancer in a woman with Graves' disease. Int J Clin Exp Med. 2012;5(4):358-62.
10. Feng Y, Spezia M, Huang S, Yuan C, Zeng Z, Zhang L, et al. Breast cancer development and progression: Risk factors, cancer stem cells, signaling pathways, genomics, and molecular pathogenesis. Genes Dis. 2018;5(2):77-106.

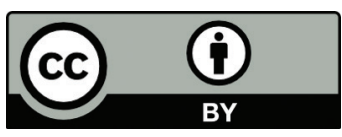

This work is licensed under a Creative Commons Attribution 